\title{
FRATERNIDADE E COOPERAÇÃO EM TEMPOS DE PANDEMIA DO SARS-COV-2: EM NOME DA CRIANÇA E DA SUA CONDIÇÃO
}

\author{
Geralda Magella de Faria Rossetto ${ }^{1}$ \\ Josiane Rose Petry Veronese ${ }^{2}$
}

DOI: https://doi.org/10.47306/978-65-88213-03-2.33-47

\begin{abstract}
Sumário: 1 Introdução: entre o propósito e o foco; 2 A pandemia do Sars-Cov-2 como fenômeno político-jurídico e sanitário e a condição da criança e do adolescente; 3 A lição da fraternidade no exercício da cooperação e da participação; $4 \mathrm{~A}$ criança, o adolescente e sua vulnerabilidade frente aos direitos à saúde e o legado do Coronavírus: cooperação e/ou segregação (?); 5 Considerações finais: a ciência e a metáfora da Fênix que sempre retorna; 6 Referências.
\end{abstract}

\section{Introdução: entre o propósito e o foco}

Será a pandemia decorrente do SARS-COV-2 capaz de contar a história do Século XXI - a firmar um tempo de transição ou de passagem - ou simplesmente estará referido vírus a atravessar a história humana?

Seja qual for a resposta, dificilmente em outro momento da humanidade, a transitoriedade e a finitude da vida estiveram tão em pauta. Outrossim, por mais que a chegada e a convivência forçada do homem com o Coronavírus seja um desafio, pode-se buscar no legado da Fênix, um ponto de mutação e de luz, capaz de incinerar o que está posto e resta inconforme, e, assim, dar forma e renascimento aos direitos dos dias atuais, mormente o direito à saúde, pela firme disposição de que precisa atender as vicissitudes que estão em evidência e, se necessário, tanto quanto a ave-mãe do "renascimento", estar pronta ao seu já renascer.

Nessa compreensão, tal qual o ninho da Fênix, feito de incenso e ervas aromáticas, para onde retorna para se lançar em direção a um novo voo, é fato que essa misteriosa ave volta para casa, em uma trajetória muito semelhante a da grande maioria das pessoas no mundo todo, e aí foram se recolher na defesa do Coronavírus, a trazer a exposição dos mais vulneráveis na dimensão de seus lares, sobretudo porque aquele lar-ninho, tal qual o da ave mitológica,

\footnotetext{
1 Doutoranda em Direito pela UFSC. Mestre em Direito pela UNISINOS. Procuradora Federal da AGU (aposentada). Membro da RUEF. Pesquisadora dos Núcleos de Pesquisa: NEJUSCA, Direito e Fraternidade, e DataLab, da Universidade Federal de Santa Catarina.

${ }^{2}$ Doutora e Mestre em Direito. Coordenadora do Núcleo de Estudos Jurídicos e Sociais da Criança e do Adolescente (NEJUSCA) e do Núcleo de Pesquisa Direito e Fraternidade, ambos do Centro de Ciências Jurídicas da UFSC. Com pós doutorado em Serviço Social na PUC/POA e em Direito na UnB.
} 
também pode ser tomado pelo que não se quer: o ninho, pelo fogo; a casa, pela violência; o lar, pelo desabrigo. Seja como for, ambos deixam de ser abrigos e necessitam do raio de luz do direito e da fraternidade.

Não é por outra razão que a escolha do tema deste estudo comporta aspectos que podem afetar diretamente a saúde de todos, em especial, conforme estão a denunciar a prática, os estudos e os dados relacionados à Covid-19, os mais expostos e fragilizados são mesmo os que estão na faixa etária igual ou superior a sessenta anos, o que não retira o aspecto de que, frente à pandemia, todos estão e necessitam de urgente proteção de seus direitos, inclusive as crianças, em razão de uma série de desafios sociais, políticos, econômicos, ambientais, culturais e jurídicos, que de outro modo, também poderão estar relacionados à violência, e, sobretudo, de negativa de direitos, em especial os relacionados aos direitos à saúde.

Esse lócus de situações oportuniza o "fiar" na fraternidade. Assim, é essencial que essa categoria (fraternidade) e, em especial o direito à saúde, sejam integrados a todo o conjunto do sistema de gestão da própria saúde, de onde decorre que o presente estudo fornece uma breve visão geral dos direitos à saúde, seu pertencimento ao conjunto dos direitos examinados, como reconhecidamente se comporta no texto constitucional e, também, se faz presente nos documentos internacionais, porquanto decorre sua também condição de convencionalidade.

A distribuição do texto, tomado para o desenvolvimento do estudo pretendido, encontra-se assim dividido, além da introdução, onde o propósito e o foco do estudo são apresentados; das considerações finais e das referências bibliográficas e outras mais: o primeiro tópico temático tem como "mote" o Sars-Cov-2 (Covid-19) como fenômeno político-jurídico e sanitário, e, com tal intento, aborda o direito à saúde em face da criança; o segundo tópico expõe a lição da fraternidade no exercício da cooperação e da participação a lhes oportunizar destaque na cena do cotidiano; o terceiro e último tópico, volta-se aos direitos à saúde, tendo a criança e o adolescente como razão e fundamento, em que o legado da Covid-19, que já vem sendo estabelecido, é neste redimensionado sob o viés da cooperação e/ou da segregação (?) no aporte da agenda de saúde, com claro objetivo: na perspectiva da fraternidade tomada como pano de fundo, verificar, no tema da saúde e de seu acesso, a especial condição de vulnerabilidade da criança, do adolescente em tempos de pandemia e, em tal decorrência, reafirmar a importância de seus direitos para esta e as futuras gerações.

A metodologia a qual se recorre para desenvolver o presente artigo, refere-se ao método de abordagem dedutivo, pelo procedimento monográfico e pela técnica de pesquisa bibliográfica, documental e, sobretudo, à análise de textos referenciais e bibliográficos, inclusive monográficos que tenham a temática em sua forma central ou transversal. 


\section{A pandemia do SARS-COV-2 como fenômeno jurídico-político e sanitário e a condição da criança e do adolescente}

De todos os acontecimentos presentes no Século XXI, certamente a pandemia que se instalou, cuja razão atende pelo nome de Covid-19, ou Coronavírus ${ }^{3}$ ou SARS-COV-2 ${ }^{4}$, está dentre os mais sombrios e assustadores acontecimentos, justamente porque coloca em perigo a vida humana e até mesmo por desvelar uma face da vida da humanidade desconhecida ou ignorada em sua mais absoluta fragilidade de exposição e risco iminente.

Em uma timeless, o mês de dezembro de 2019 marca diversos casos de pneumonia que surgiram em Wuhan, província de Hubei, China. Isolado o vírus, a análise do material genético revelou que se trata de um novo betacoronavírus, denominado 2019-nCoV pela Organização Mundial da Saúde (OMS) (BRASIL, 2020a). Mais recentemente, o mesmo foi chamado de SARS-CoV-2 (do inglês Severe Acute Respiratory Syndrome Coronavirus2) (BRASIL,2020a), de forma que, "a escala da praga Covid-19 é surpreendente, mas não a sua aparição" (CHOMSKY, 2020, p. 152).

Segundo registra o Ministério da Saúde brasileiro, a doença se espalhou rapidamente pelo território chinês e, posteriormente, pacientes infectados por SARS-CoV-2 foram identificados em outros países, principalmente na Europa (tendo como epicentros a Itália e a Espanha), nos Estados Unidos, no Canadá e no Brasil. Em 30 de janeiro de 2020, a OMS declarou a doença como uma emergência de saúde pública global e, em 11 de março de 2020, ela passou a ser considerada uma pandemia. Nessa data, o Governo do Distrito Federal já tomou algumas providências de isolamento, servindo de exemplo para os demais Estados da federação (BRASIL, 2020a).

A Covid-19 foi caracterizada como "pandemia” pela OMS em 11 de março de 2020: “O termo 'pandemia' se refere à distribuição geográfica de uma doença e não à sua gravidade. A designação reconhece que, no momento, existem surtos de Covid-19 em vários países e regiões do mundo" (OPAS BRASIL, 2020a).

$\mathrm{Na}$ ordem das instituições ou do Estado, na realidade brasileira, a corrupção, a impunidade, as divergências políticas, a desinformação, a falta de comunicação, extensiva a falta de voz de seus atores e autores, corroboram para que seus cidadãos e cidadãs tenham sempre que ir em busca do exercício de seus direitos. Em um contexto de repressão e até de insegurança jurídica pela falta adequada de acesso à justiça, em que a força e o projeto político

\footnotetext{
${ }^{3}$ No rigor da expressão científica, o nome corresponde ao da família de vírus a que ele pertence (Coronaviridae).

${ }^{4}$ Sars-CoV-2, significa "síndrome respiratória aguda grave - Coronavírus 2".
} 
estão a medir posição entre si, o que dá conta da presença de muitos protestos sociais e a propagação de inúmeras fake news, assim como atos de vandalismo; graves crises penitenciárias; a migração, a locomoção forçada interna de pessoas refugiadas e apátridas, assim como a discriminação contra grupos, muito mais, os que se encontram em situação de especial vulnerabilidade, historicamente excluídos ou que se encontram em especial risco, tal como, dispõe a Resolução 01/2020 (CIDH - OEA), que trata da "Pandemia e Direitos Humanos nas Américas", adotada pela Comissão Interamericana de Direitos Humanos - CIDH em 10 de abril de 2020:

[...] personas mayores y personas de cualquier edad que tienen afecciones médicas preexistentes, personas privadas de libertad, mujeres, pueblos indígenas, personas em situación de movilidad humana, niñas, niños y adolescentes, personas LGBTI, personas afrodescendientes, personas com discapacidad, personas trabajadoras, $\mathrm{y}$ personas que vivenen pobreza y pobreza extrema, especialmente personas trabajadoras informales y personas em situación de calle; así como em las defensoras y defensores de derechos humanos, líderes sociales, profesionales de la salud y periodistas.

Teniendo en particular consideración que enel contexto de pandemia, por lo general, los cuidados de las personas enfermas o necesitadas de especial atención recaen fundamentalmente em las mujeres, a expensas de su desarrollo personal o laboral, existiendo um escasso nivel de institucionalización y reconocimiento social o económico para tales tareas de cuidados que en tiempo de pandemia se vuelven aún más necesarios y exigentes.

Nesse contexto em que os legados da violência encontram-se frescos na memória, tudo leva a uma pandemia de difícil deliberação, com supostos desafios para os Estados, tanto quanto na dimensão política e de medidas sanitárias, como na esfera econômica, com evidente dificuldade na condução de medidas de atenção e contenção que resultem urgentes, necessárias, evidentes ou não, incluindo medidas que facilitem e que atendam o diagnóstico, o tratamento oportuno, razoável e exequível, a despeito de inexistência de condução farmacêutica viável, tal como o medicamento acertado e até mesmo o desconhecimento de vacina apropriada na batalha contra o Coronavírus.

A despeito de que não há posição científica clara e confirmada sobre a posição farmacêutica, médica, epidemiológica e sanitária na condução do tratamento da Covid-19, o que tem levado a posicionamentos divergentes, em termos políticos, jurídicos, sociais, econômicos e sanitários. Além de que, segundo Chomsky, a chocante, atrasada e limitada testagem, bem abaixo de outros, tem impossibilitado implementar as estratégias bem-sucedidas de teste e rastreamento, a impedir a epidemia de sair do controle onde foi implementada (2020, p. 156).

A respeito das condições, protocolos e diretrizes farmacêuticas, condutas médicas e farmacêuticas tem-se segundo a lição de Ventura: 
A gramática da vigilância epidemiológica compreende a quarentena, a limitação ou interdição de viagens, o recrudescimento do controle fronteiriço ou mesmo o fechamento de fronteiras, a imposição de terapias, a restrição ou supressão de reuniões públicas, a vacinação obrigatória, ou até ingerências no modo como se realizam os funerais $(2009$, p. 160-161).

No Brasil, além das questões iminentes à pandemia, na seara governamental, trava-se conjuntamente uma outra expedição, de cunho político, a qual condiz com punição, derrubada de ministro(s) e outros tipos de ingerências na soberania nacional e política do país. A defesa da democracia, a defesa do livre mercado, a defesa da livre manifestação da cidadania ante o Estado opressor, a defesa da segurança nacional e até a própria defesa dos direitos, como sói decorrer do direito à saúde, precisa ser retomada na linha que constitui, na ordem da contemporaneidade, instalada pela Covid-19, um dos pilares da classificação dos direitos humanos, dos direitos fundamentais e dos direitos sociais, inclusive para que se possa dar ênfase aos direitos dos que estão em limites de vulnerabilidade, como muitas vezes ocorrem com os direitos da criança.

Corroborando, conforme consta das diretrizes e protocolos do Regulamento Sanitário Internacional (RSI) $)^{5}$, a ESPII é considerada "um evento extraordinário que pode constituir um risco de saúde pública para outros países devido a disseminação internacional de doenças; e potencialmente requer uma resposta internacional coordenada e imediata". (OPAS BRASIL 2020b).

Conforme se depreende, referida decisão teve o condão de "aprimorar a coordenação, a cooperação e a solidariedade global para interromper a propagação do vírus" (OPAS BRASIL, 2020a), o que significa que as medidas de saúde recomendadas possuem caráter emergencial, de cunho temporárias e são a chave para prevenir ou reduzir a propagação mundial de doenças. Também, em tais decorrências, está aberta a proposta para a presença da fraternidade.

\section{A lição da fraternidade no exercício da cooperação e da participação}

Os tempos dificeis, como sói acontecer com estes que se seguem, premidos pela Pandemia do Sars-Cov-2, têm revelado o herói, do mesmo modo que dá conta do covarde. Mais, forma o sábio e, também, o ignorante, porque fornece as bases de uma educação. De outro

\footnotetext{
${ }^{5}$ Conforme consta: "O Regulamento Sanitário Internacional (RSI) é um instrumento jurídico internacional vinculativo para 196 países em todo o mundo, que inclui todos os Estados Membros da Organização Mundial da Saúde (OMS). Seu objetivo é ajudar a comunidade internacional a prevenir e responder a graves riscos de saúde pública que têm o potencial de atravessar fronteiras e ameaçar pessoas em todo o mundo". (OPAS BRASIL, 2020b).
} 
modo, expõe a humanidade de cada um e de todos, justamente por revelar o quadro da dor e do sofrimento.

Sobretudo, o Coronavírus poderá dividir a história humana, em antes e em depois, ou, simplesmente, fazer-se rito de passagem, tempo de transição que se vive e que se vai, além de ter mostrado a indesejável presença de uma pandemia para os seres humanos. "E talvez isso ainda não seja tudo: estamos presenciando o crescente conflito de classes entre ricos e pobres, tensões entre o mundo industrializado e o em desenvolvimento, entre Estados democráticos e autoritários" (DITCHEV, 2020).

Harari, a respeito desses dias, observa:

Mas espero que consigamos desenvolver nossa compaixão, e não nosso ódio, e reagir
com solidariedade global, desenvolvendo nossa generosidade de ajudar os
necessitados. E que desenvolvamos nossa capacidade de discernir a verdade, em vez
de acreditar em todas essas teorias da conspiração. Se fizermos isso, não tenho dúvida
que conseguiremos superar facilmente a crise. (2020a).

Além do mais, é fato que "os principais desafios que as pandemias trazem ao Direito são, em primeiro lugar, como garantir o direito à saúde em contextos de exacerbação da crise" (VENTURA, 2009, p. 161). Referida condição é, sem dúvida, incomensurável e apresenta complexidades de ordem tal que somente a colaboração, a cooperação, a solidariedade, e, por assim dizer, uma robusta condição de fraternidade, presente na condição humana e no estabelecimento de sua organização, estão aptas a desvelar.

De outro modo, Harari a respeito dos dias atuais, em que a pandemia está entre nós, o que traz a tona a necessária humildade (não no sentido religioso tradicional), a dar conta da consciência da nossa impermanência e fragilidade, o que é real, e, por fim, aponta a importância do tempo e o que fazer dele (2020b).

O cenário de incertezas e, também de descobertas, fornece vez e voz à fraternidade. Não que o contrário dispensasse a sua presença. Já é tempo, tardiamente, de se entender de uma vez por todas a fundamentalidade de sua presença a dar arranjo aos direitos. Por mais que a fraternidade tenha sido tratada como "esquecida", são seus fatos, dados e a sua própria história que agilizam a condição humana, especialmente nesses dias em que a pandemia tem despertado demandas de sofrimento e de dor, inauguradores de acentuados riscos da própria vida e de sua condição.

Por vezes, o conhecimento humano insiste no caminho mais complicado. Outras não. Quando o bom senso e a razoabilidade, de que se nutre a cooperação e da qual se pode buscar e encontrar um lugar de participação, facilmente faz-se presente o ânimo fraterno e seu par substantivo - a fraternidade. 
$\mathrm{Na}$ medida em que a fraternidade torna possível a coparticipação da humanidade inteira, seja através das mesmas alegrias, das mesmas dores, é a participação voltada à cooperação que desvela seu maior talento: o dar-se em consideração pelo outro, pelos sofredores e, de modo genuíno, para os últimos da Terra, ou, no dizer de Saramago, em nome da "irmandade de condenados da terra."6 (SARAMAGO, 2018).

De outro modo, o discurso do Coronavírus que deveria ser feito no oportuno tempo passado $^{7}$, porém, quando tal adveio, a urgência demandou em tragédia anunciada, e até mesmo ocasionou um certo esquecimento - o que é bem próximo do que sucedeu à própria fraternidade - ela que tem na sua história, uma falta de aprovação, a ponto de conferir à sua condição, a marca de sua transitoriedade, para não dizer a ausência de seu reconhecimento.

Outro aspecto importante é o fato de que a fraternidade tem emprestado contribuição à consolidação da normatividade constitucional, o que tem sido reafirmado pela jurisprudência, com o propósito de conferir o contraponto e sustentação à temática ${ }^{8}$, em especial ao conceito de fraternidade, o que, em termos de defesa dos direitos, sua lição é digna da melhor fita métrica: prestar ouvidos ao modo de "escolha" e atuação da sociedade em seu processo normativo, a dar sustentação ao seu correspondente processo decisório.

É essencial que a fraternidade e o direito à saúde, como fruto dos direitos humanos, sejam integrados a todo o conjunto do sistema de gestão da própria saúde; isso posto, o presente artigo fornece uma breve visão geral dos direitos à saúde, seu pertencimento aos direitos fundamentais e aos direitos sociais, como reconhecidamente se comporta inclusive no texto constitucional e, também, se faz presente no texto de documentos internacionais, porquanto decorre sua também condição de convencionalidade.

Seja por que viés for, é preciso reconhecer que os seres humanos são transitórios em sua passagem pela terra, e, em tal razão, há de se facilitar a continuidade da vida - no que muito

\footnotetext{
${ }^{6}$ Saramago, sobre essa "gente popular" (2020) aponta: “[...] Camponeses rudes obrigados a alugar a força dos braços a troco de um salário e de condições de trabalho que só mereceriam o nome de infames, cobrando por menos que nada a vida a que os seres cultos e civilizados que nos prezamos de ser apreciamos chamar, segundo as ocasiões, preciosa, sagrada ou sublime" (2020).

${ }^{7}$ A origem, o avanço e a história da propagação do Coronavírus não se devem ao agora. Senão, veja-se: "Ao todo, sete coronavírus humanos (HCoVs) já foram identificados: HCoV-229E, HCoV-OC43, HCoV-NL63, HCoVHKU1, SARS-COV (que causa síndrome respiratória aguda grave), MERS-COV (que causa síndrome respiratória do Oriente Médio) e o, mais recente, novo coronavírus (que no início foi temporariamente nomeado 2019-nCoV e, em 11 de fevereiro de 2020, recebeu o nome de SARS-CoV-2). Esse novo coronavírus é responsável por causar a doença COVID-19”. (OPAS-BRASIL, 2020).

${ }^{8}$ Os tribunais brasileiros têm se posicionado favoráveis ao tema da Fraternidade. O seu reconhecimento pode ser visto no fundamento seguinte, extraído do $r$. decisum, de relatoria do Ministro Reynaldo Soares da Fonseca: "Por outro lado, a proteção da integridade física e emocional dos filhos decorre, indiscutivelmente, do resgate constitucional do princípio da fraternidade (Constituição Federal: preâmbulo e art. $3^{\circ}$ )". (Habeas Corpus n ${ }^{\circ} 562452$ - SC (2020/0040462-5), (BRASIL, 2020b). Nesse mesmo e igual sentido, também, o Habeas Corpus n 554892 RO (2019/0385486-2), de relatoria do MINISTRO Reynaldo Soares da Fonseca (BRASIL, 2020c).
} 
a fraternidade pode contribuir. É por razões como essa, que a fraternidade tem emprestado profundo significado às relações humanas e aos seus direitos, notadamente aos direitos à saúde, custosamente construídos, uma vez que as pessoas pertencem a grande e única família humana, em que o indivíduo se põe em relação de horizontalidade com o outro - seu par e seu irmão em uma ordem de compromisso, de respeito e de cooperação, cuja permissão confere reconhecimento a todos os direitos presentes nas relações estabelecidas pelos seres humanos.

\section{A criança, o adolescente e sua vulnerabilidade frente aos Direitos à Saúde e o legado do Coronavírus: cooperação e/ou segregação (?)}

Este ponto aborda o conjunto dos direitos em face da criança e do adolescente, tendo como aporte a promoção, proteção e defesa de seus direitos, com ênfase, ao direito à saúde que em termos de pandemia - pela transitividade internacional requer ser traçado sob a dimensão dos Direitos Sociais, dos Direitos Fundamentais e dos Direitos Humanos, de onde decorre a importância dos preceitos internacionais - sobretudo, a Convenção Americana dos Direitos Humanos e a Convenção sobre os Direitos da Criança; as disposições constitucionais pertinentes - no caso a Constituição Federal de 1988; a legislação nacional - em especial o Estatuto da Criança e do Adolescente; e os aspectos regulamentados, com ênfase aos pertinentes à pandemia de que dão conta os protocolos e as diretrizes relacionadas. O rigor é metodológico, axiológico e epistemológico, justificando brindar a cientificidade, o necessário método e o apuro da lexia.

Adiante-se, contudo, que o interesse chave deste estudo, volta-se aos direitos à saúde em face da criança e do adolescente, exatamente os que se assentam na ordem material e prestacional dos interesses dos "pequenos", com perspectivas de serem garantidos pelo Estado, e no que colaboram tanto a sociedade em geral e a própria família.

Apesar das infecções por coronavírus geralmente serem consideradas leves, nas epidemias por SARS-CoV em 2002, e MERS-CoV (Middle East Respiratory Syndome) em $2012(7,8)$, mais de 10.000 pessoas foram infectadas, com taxas de mortalidade de $10 \%$ e 37\%, respectivamente. Sendo assim, a infecção pelo vírus SARS-CoV-2 causa a Covid-19 (Coronavirus Disease 2019) (BRASIL, 2020a). Em relação às crianças, escondidas por trás dos números ${ }^{9}$, a questão pode parecer insignificante, porém há o compromisso de proteger a geração do agora e a do futuro.

\footnotetext{
${ }^{9}$ O Boletim Epidemiológico Especial - COE Covid-19, da Secretaria de Vigilância em Saúde do Ministério da Saúde, fornece análise detalhada sobre a Covid-19 no Brasil, por unidade da Federação, e, também, a interpretação
} 
Nos dias atuais, em que a convivência obrigatória da pandemia da Covid-19 - que se arrasta sem trégua - vem sendo reeditada frequentemente em todos os continentes, países e cidades, outros temas dali decorrem, interligados à urgência de direitos que precisam de "socorro" imediato. Sob a máscara do "isolamento", da segregação, ou do distanciamento, a cooperação vem sendo fragilizada e precisa de igual urgência, tanto quanto o direito à saúde requer. Dessa constatação, sobressai a preciosidade das lições relativas à categoria da fraternidade. Associadas, serão possíveis uma forte realização e entrega inteligente de direitos.

A pandemia desencadeada pelo Coronavírus está a afetar a concretização dos direitos - em especial os direitos à saúde - de toda a população e a colocar em sérios riscos a vida, a saúde física e mental e a integridade pessoal. Agir, a favor da vida e não do mercado, sem discriminação, diminuindo impactos sobre toda a sociedade e o próprio Estado, os governos e os governantes, as pessoas em geral e, especialmente, as pessoas e grupos reconhecidamente em vulnerabilidade, equivale a afastar de forma inteligente e com profundidade o que a patologia tem revelado e atuado de forma dramática e assassina contra os que estão em dificuldade de toda sorte: o que é um dos gargalos no enfrentamento da pandemia.

No cenário do Coronavírus, um bom filtro de definição dos vulneráveis tem a ver com a quarentena. É que, no dizer de Santos (2020, p. 15), qualquer quarentena é sempre discriminatória, porque mais difícil para uns do que para outros, quando não impossível para outros tantos, como os que estão a tornar possível a quarentena ao conjunto da população. Assim, para alguns grupos sociais cuja história comum é uma especial vulnerabilidade a preceder e ser agravada pela quarentena, o que a torna mais agravada e particularmente difícil.

Nesse viés, o Brasil se coloca no cenário mundial, como um dentre os países mais desiguais do planeta, típico da existência de profundas cisões e fraturas sociais, cujos exemplos a pobreza, a miserabilidade e a hipossuficiência extrema constituem problemas frequentes em todos os Estados, assim como, também, problemas outros adjacentes, que atendem pela precariedade da água potável, do saneamento, da falta de moradia e da habitação adequada, da alimentação e da insegurança ambiental, para citar alguns exemplos, sem o condão de exaurilos. A isso se somam, as altas taxas de desemprego, informalidade laboral, parcas economias, poucos ou pífios ingressos no mercado de trabalho especializado, escolaridade baixa, o que dão

da condição epidemiológica, evidências, limitações e enfrentamento. Nos gráficos e números ali listados, não raros, também estão os dados de crianças, vítimas precoces dessa doença. Para maiores detalhes, consulte referido boletim. Disponível em: https://portalarquivos.saude.gov.br/images/pdf/2020/May/21/2020-05-19---BEE16--Boletim-do-COE-13h.pdf. Acesso em: 20 maio 2020. 
conta de um efetivo impacto social, econômico e político quando em contraponto ao Sars-Cov2 .

Tudo isso representa clara dificuldade ou impedimento a milhões de pessoas ter em seu cotidiano medidas básicas de prevenção contra doenças, em particular, estando a afetar grupos em situação de especial condição, dentre os quais estão, na ordem pessoal, os de especial vulnerabilidade, sobretudo os que engrossam as estatísticas, as listas e os índices de violência em geral, especialmente, por razões de gênero, de raça ou de etnia.

No Brasil, conforme informam os meios de informação e as autoridades públicas, inclusive o próprio Poder Judiciário brasileiro, sobretudo, as autoridades epidemiológicas, sanitárias e médicas, diferentes medidas têm sido adotadas para tentar conter a infecção desencadeada pela Covid-19. Dentre as muitas conhecidas, tem-se a segregação, a adoção de máscaras, a indicação da boa alimentação, e a adoção de pesada carga de limpeza, que a todos se submetem.

Em consonância com outras iniciativas, o Ministério da Saúde, por meio de diferentes departamentos, tem reunido esforços no sentido de organizar os serviços de saúde para o atendimento de pacientes com suspeita ou diagnóstico confirmado da Covid-19, bem como de qualificar esse atendimento. Entre essas medidas, convém o destaque, do documento intitulado “Diretrizes para Diagnóstico e Tratamento da Covid-19”, que tem como objetivo apresentar as diretrizes de prevenção, diagnóstico, tratamento e monitoramento dessa doença. Também, o do Plano de Contingência Nacional para Infecção Humana pelo novo Coronavírus, coordenado pela Secretaria de Vigilância em Saúde (SVS), o Protocolo de Manejo Clínico do Coronavírus (Covid-19) na Atenção Primária à Saúde, da Secretaria de Atenção Primária à Saúde (SAPS), a Nota Informativa n. 6/2020 - DAF/SCTIE/MS, entre outros documentos (BRASIL, 2020a).

Há, contudo, de se dar destaque, à elaboração das Diretrizes para Diagnóstico e Tratamento da Covid-19, enquanto resposta ao seu enfrentamento, em face da presença e declaração de pandemia firmada pela Organização Mundial de Saúde e as iniciativas do Ministério da Saúde para enfrentamento dessa situação no Brasil, levando-se em conta que as diretrizes são dinâmicas e terá versões provisórias e atualizações periódicas, acompanhando a produção de novas evidências para estabelecer outras novas recomendações (BRASIL, 2020a).

Ora, esse "desenho" pode não corresponder à realidade. Entretanto, a pandemia desencadeada pelo Coronavírus escancarou a condição humana, sobretudo, da população verdadeiramente vulnerável, quais sejam, além dos idosos e grupos de risco, as famílias de comunidades pobres, moradores de rua e, em especial, crianças e adolescentes, para citar alguns, de forma que, não há como negar que a estadia da Covid-19 expõe a fragilidade das 
políticas voltadas a essas pessoas, que já vinham ocupando menos espaço no orçamento, e está a demonstrar como a desigualdade no Brasil consegue ser ainda mais perversa com essas camadas da população, expostas em situações-limite.

De outro modo, a convivência e a vivência com a pandemia Covid-19, tem instalado entre nós, a necessidade de uma igualdade, tão ansiada e negativamente vivida, como também, de certo modo tem despertado às instituições a necessidade da intersetorialidade entre as instituições, a auxiliar de forma direta, a retomada dos direitos alusivos à saúde e sua entrega a cada pessoa.

Ainda, a respeito dos diferentes direitos e necessidades presentes na realidade das diferentes faixas etárias. Por várias razões, os mais velhos estão em situação de fragilidade, quando comparados aos mais jovens. De um lado, enquanto as crianças e adolescentes, que deveriam estar protegidos pela adequada proteção integral, têm seus direitos envolvidos na mais complexa demanda de retração de direitos, que vão desde a aceleração da virtualidade a proporcionar pífio envolvimento social, o desprestígio da educação formal, o prejuízo e até a ausência da companhia e do convívio familiar, o aumento da violência.

Portanto, seja no comando da sociedade, da família, e/ou da esfera do agir estatal, são esperados adequada orientação e instrução jurídica à proteção de sua saúde. A atuação em contrário, compartilha de legado atentatório a sua dignidade, configurador de violação de direitos e, portanto, denunciador de uma política contraditória e violenta.

Aliás, até mesmo no regaço familiar, em que o lar é o destino dos componentes do grupo familiar e a moradia oferece pouca condição ou se faz ausente, tal, detém por si, uma realidade denunciadora de precariedades, a oferecer mínima proteção contra a Covid-19, o que é comum nas famílias de comunidades pobres, moradores de rua e, em especial, quando diz respeito às crianças e adolescentes - esses, apesar de deterem prioridade absoluta de acordo com a Constituição Federal de 1988, muitas vezes estão fora do alcance de certos direitos, o que demanda uma atuação em fraternidade.

\section{Considerações Finais: a ciência e a metáfora da Fênix que sempre retorna}

A atenção à tutela dos direitos, em particular para os mais pobres ou com dificuldade financeira, ou, em uma única locução: os que se encontram em vulnerabilidade - ou mesmo para quem se encontra fora da cobertura médica e até mesmo para o caso de necessitarem de atendimento médico e hospitalização - necessitam de atenção redobrada, porque, de outro modo, a resposta à crise, "ofertará" um custo impagável e complicado, principalmente para os vulneráveis e os mais pobres. 
Também, quanto às crianças e aos adolescentes, nos cenários de transmissão comunitária, elas necessitam de especial deferência, no vislumbre de que há uma vida a ser atendida pela proteção integral. Além do mais, em relação aos mais pobres e necessitados, a Living guideline recommendations ${ }^{10}$ requer seja reforçada.

Pela dinâmica da epidemia e da produção de conhecimento associada a ela, é preciso levar em consideração, conforme avançar os estudos e as respostas sobre a doença, também vão se assentar os protocolos voltados à atenção e à estratégia relativos à saúde, da qual não escapam também os interesses da criança.

A discussão que se estabelece em torno dos direitos da criança e do adolescente, em especial os relativos à saúde, tendo como contexto o momento atual, em que se vive uma encruzilhada traçada pela pandemia do Coronavírus, é, desde sempre, marcada por uma abordagem contraditória que cresce com o estabelecimento da insegurança do que fazer, a objetivação da vida vai ganhando corpo, e, muito mais, pelo desprezo e esquecimento de que os seres humanos são todos absolutamente iguais e estão a habitar a mesma terra e usufruir da mesma e igual natureza. O ideal é a referência à fraternidade.

Em relação à criança e ao adolescente, ainda que titular da proteção integral, a sua condição e vulnerabilidade deveriam por si receber a tutela e segurança dos direitos à saúde, e, bem por isso, seus direitos não poderiam estar sendo questionados ou submetidos à violação.

Atente-se que a humanidade já viveu outras pandemias, como aconteceu com a gripe espanhola, ou até mesmo, em períodos próximos, em relação a H1N1 (2009); a disseminação internacional de poliovírus (2014); o surto de Ebola na África Ocidental (também em 2014); o vírus zika e o aumento de casos de microcefalia e outras malformações congênitas (2016); e o surto de ebola na República Democrática do Congo $(2018)^{11}$. Em duas delas, a saúde das crianças foi diretamente atingida e, em todas, esteve seriamente sujeita a sérios comprometimentos.

Muitas ações, situações e motivos poderiam ser listados a par dessa realidade, de que dão conta as constantes exigências de segurança dos direitos, os interesses de mercado, a reorganização das esferas da saúde pública, higiene simples e orientada, o uso de medicamentos, a sobressalência de aspectos políticos - tal como o (não) reconhecimento da autoridade sanitária como ponto central de organização, de gestão e regulação relacionada ao

\footnotetext{
${ }^{10}$ Em tradução literal: Recomendações para diretrizes de vida.

11 "É a sexta vez na história que uma Emergência de Saúde Pública de Importância Internacional é declarada" (OPAS BRASIL, 2020a).
} 
tema; informações baseadas na ciência e autoridades públicas nas quais se pode confiar pode salvar milhões de vida.

Com efeito, o conjunto dessas situações, amparados em um cenário globalizado, corroboram com a gradual diminuição de garantias e valores ditos essenciais a um Estado Democrático de Direito, não é por outra razão, senão a cooperação, amparada no seu sentido estabelecido pela fraternidade, que se pode dar conta de um mundo de saúde minimamente seguro e eficaz.

Também a ciência não deveria estar nesse atual estágio atrás de uma busca que poderá levar anos. Se por ocasião da primeira manifestação do Coronavírus humano (HCoVs) - já foram identificados sete deles - até chegar ao novo Coronavírus, responsável por causar a doença Covid-19, a discussão e o debate, incluindo a promoção da pesquisa, tivesse sido reforçada, é possível que a medicação, o protocolo e até mesmo a vacina poderiam ter sido obtidos, ou pelo menos, estivessem avançados neste momento.

Ao contrário, frente a uma ciência que precisa constantemente ser revista, socorre uma ciência viva, em constante mutação. Tal qual advém da lição da Fênix, essa ave de plumas vermelhas e douradas, que segundo a literatura, renasce das cinzas - representando a vida que sempre retorna, em seu ciclo interminável, a embalar um ovo de mirra ${ }^{12}$, cuja metáfora dá conta da relação da criança e sua mãe, pronta ao cuidado, sempre disposta a defendê-la. Comparada à Fênix, será essa a eterna e incessante tarefa da mãe-cientista zelosa, cuidadora do mundo, a se arriscar noite e dia à descoberta que há de advir: assistir à vida e, se preciso, buscar o antídoto, o frasco valioso do remédio que custa, insiste e tarda a chegar, a sarar a vida e a cuidar dos direitos de suas crianças e adolescentes do mundo.

\section{REFERÊNCIAS}

BRASIL. Boletim Epidemiológico Especial-COE Covid-19. Secretaria de Vigilância em Saúde do Ministério da Saúde. Disponível em: https://portalarquivos.saude.gov.br/images/pdf/2020/May/21/2020-05-19---BEE16---Boletimdo-COE-13h.pdf. Acesso em: 20 maio 2020.

\section{BRASIL. Ministério da Saúde: DIRETRIZES PARA DIAGNÓSTICO E}

TRATAMENTO DA COVID-19. Brasília-DF, 06 de abril de 2020. Disponível em: http://www.sbac.org.br/blog/2020/04/09/diretrizes-para-diagnostico-e-tratamento-da-covid19/. Acesso em: 17 de abr. 2020a.

\footnotetext{
${ }^{12}$ Segundo revela a mitologia, "quando sentia que ia morrer, a fênix montava um ninho com incenso e outras ervas aromáticas para ser incinerada pelos raios do Sol. De suas cinzas, nasceria uma nova ave. Assim que se sentia forte, a nova fênix embalava as cinzas de onde surgiu em um ovo de mirra e o transportava para o templo do deus Rá, na cidade de Heliópolis". Disponível em: https://super.abril.com.br/mundo-estranho/onde-surgiu-e-o-querepresenta-a-mitologica-ave-fenix/. Acesso em: 07 maio 2020.
} 
BRASIL. SUPERIOR TRIBUNAL DE JUSTIÇA. Disponível em: https://ww2.stj.jus.br. Acesso em: 15 maio 2020a.

BRASIL. SUPERIOR TRIBUNAL DE JUSTIÇA. Disponível em: https://ww2.stj.jus.br.Acesso: em 15 maio 2020b.

CHOMSKY, Noam. In: TOSTES, Anjuli; MELO FILHO, Hugo (organizadores).

Quarentena: Reflexões sobre a Pandemia e Depois. Ilustração Carlo Giambarresi. Projeto Ed. Praxis. 1. ed., Bauru-SP: Canal 6 Editora, 2020, p. 151-161.

DITCHEV, Ivaylo. In: DW Deutsche Welle. Coronavírus traz fronteiras de volta à Europa. Notícias Mundo. 21 abril 2020. Disponível em: https://www.dw.com/ptbr/opini\%C3\%A3o-coronav\%C3\%ADrus-traz-fronteiras-de-volta-\%C3\%A0-europa/a53197900. Acesso em: 29 abr.2020.

HARARI, Yuval Noah. Entrevista à DW: "Maior perigo não é o vírus, mas ódio, ganância e ignorância". Disponível em: https://www.dw.com/pt-br/yuval-noah-harari-maior-perigon\%C3\%A3o-\%C3\%A9-o-v\%C3\%ADrus-mas-\%C3\%B3dio-gan\%C3\%A2ncia-eignor\%C3\%A2ncia/a-53232884. Acesso em: 30 abr. 2020a.

HARARI, Yuval Noah. Coronavírus não vai mudar a crença de que é possível vencer a morte. Folha de São Paulo. 02 de maio de 2020b. Disponível em:

https:/www1.folha.uol.com.br/ilustrissima/2020/05/coronavirus-nao-vai-mudar-a-crenca-deque-e-possivel-vencer-a-morte-diz-harari.shtml. Acesso em: 02 maio 2020.

HARARI, Yuval Noah. 'Guru' dos nossos tempos, Yuval Harari aponta os cenários póspandemia. (Breve Companhia, Ensaio). In: SAHD, Luiza, 28 março de 2020 (atualizado em 01 abril de 2020). Disponível em: https://tab.uol.com.br/noticias/redacao/2020/03/28/gurudos-nossos-tempos-yuval-harari-aponta-os-cenarios-pos-pandemia.htm. Acesso em: 09 abr. 2020 .

MARIANELLI, Massimiliano. Os mitos e a fraternidade entre os homens: Simone Weil e o "lugar" do encontro. In: BAGGIO, Antonio Maria (organizador). Traduções Durval Cordas, Luciano Menezes Reis. O Princípio Esquecido/2: Exigências, recursos e definições da fraternidade na política. Vargem Grande Paulista-SP: Editora Cidade Nova, 2009, p. 175-193.

OPAS BRASIL. Folha Informativa - COVID-19 (doença causada pelo novo Coronavírus). Principais Informações.

https://www.paho.org/bra/index.php?option=com_content\&view $=$ article\&id=6101:covid19\&I temid=875. Acesso em: 19 maio 2020a.

OPAS BRASIL. Regulamento Sanitário Internacional. Disponível em:

https://www.paho.org/bra/index.php?option=com_content\&view=article\&id=5847:regulamen to-sanitario-internacional-rsi\&Itemid=812. Acesso em: 20 maio $2020 \mathrm{~b}$.

Ministério da Saúde: DIRETRIZES PARA DIAGNÓSTICO E TRATAMENTO DA COVID-19. Brasília-DF, 06 de abril de 2020. Disponível em: http://www.sbac.org.br/blog/2020/04/09/diretrizes-para-diagnostico-e-tratamento-da-covid19/. Acesso em: 17 abr. 2020.

Resolução 01/2020: "Pandemia e Direitos Humanos nas Américas” (OEA e CIDH). Adotada pela Comissão Interamericana de Direitos Humanos - CIDH, em 10 de abril de 
2020. Disponível em: http://www.oas.org/es/cidh/decisiones/pdf/Resolucion-1-20-es.pdf. Acesso em: 17 abr. 2020.

SANTOS, Boaventura de Sousa. A Cruel Pedagogia do Vírus. Coimbra-PT: Almedina Biblioteca Nacional de Portugal, 2020.

SARAMAGO, José. In: Fundação José Saramago. Discurso pronunciado a 7 de Dezembro de 1998 na Academia Sueca (por ocasião da Premiação Nobel) - De como a personagem foi mestre e o autor aprendiz. Disponível em:

https://www.dropbox.com/s/ly47putkg2664me/discursos_estocolmo portugues.pdf. Acesso em: 20 maio 2020.

VENTURA, Deisy. Pandemias e Estado de Exceção. In: CATTONI, Marcelo; MACHADO, Felipe (Coordenadores). Constituição e Processo: a resposta do constitucionalismo à banalização do terror. Belo Horizonte: Del Rey, 2009, p. 159-181. 